\section{Perspectives on the photoelectrochemical storage of solar energy}

Roel van de Krol, Helmholtz-Zentrum Berlin für Materialien und Energie GmbH, Institute for Solar Fuels, Berlin 14109, Germany

Bruce A. Parkinson, Department of Chemistry and School of Energy Resources, University of Wyoming, Laramie, Wyoming 80271, USA

Address all correspondence to Roel van de Krol at roel.vandekrol@ helmholtz-berlin.de

(Received 24 August 2017; accepted 31 October 2017)

\title{
ABSTRACT
}

\section{Direct photoelectrochemical water splitting offers several advantages over PV-powered electrolysis and may become the technology of choice in the future. However, significant $R \& D$ efforts and breakthroughs are needed to accomplish this goal.}

The sustainable production of hydrogen would be an important first step for both powering fuel cells and for enabling large-scale and technologically mature gas phase processes to reduce $\mathrm{CO}_{2}$ and nitrogen to get desired products. Specifically, the central challenge is to produce hydrogen from water using sunlight. Photovoltaics and wind-powered electrolysis are likely to be the technology of choice to produce renewable hydrogen for the next few decades. However, the integration of light absorption and catalysis in 'direct' photoelectrolysis routes offers several advantages, such as lower current densities and better heat management, and may become technologically relevant in the second half of this century. This article discusses the research and development efforts and needed breakthroughs to achieve this goal. New chemically stable semiconductors with a band gap between 1.5 and $2.0 \mathrm{eV}$ and long carrier lifetimes are urgently needed to make efficient tandem devices. Scale-up of these research level devices beyond a few $\mathrm{cm}^{2}$ introduces mass transport limitations that require creative electrochemical engineering solutions. Last but not least, standardized methods for measuring efficiencies and stabilities need to be implemented and should lead to official benchmarking and certification laboratories to guide commercial scale up efforts.

Keywords: photochemical; energy storage; energy generation

\section{DISCUSSION POINTS}

- Water splitting will be a central challenge for any future fossil fuel-free energy infrastructure that relies on liquid or gaseous chemical fuels.

- While the main materials challenge for solar- and wind-driven electrolysis is the development of better catalysts, the main challenge for photoelectrochemical water splitting is to find new chemically stable optimal-bandgap semiconducting light absorbers.

- Further progress in the development of photo-driven water splitting generators requires significant additional efforts in electrochemical engineering and the development of standardized methods for benchmarking device performance and stability.

\section{Introduction}

There has been a world-wide effort in the last decade to accelerate the progress of research on converting and storing solar energy especially in the form of chemical bonds. Major centers for solar fuels research, and programs within the national science foundations and energy departments, have been funded to attack this problem with a total world-wide expenditure of over $\$ 750$ M. $^{1}$ Attainment of the noble goal of having a greenhouse gas-free energy economy depends on the fact that solar fuels have to compete with extracting reduced carbon or hydrocarbon fuel sources. Currently, the extraction of these resources does not require a large capital investment in covering large areas with solar collectors for the generation of energetic electrons and holes since much of the investment is already in place. Therefore, without the governments of the world putting a price on $\mathrm{CO}_{2}$ emissions, either with a carbon tax or cap and trade policy, solar fuels will not be economically viable until these carbon-based resources are largely depleted and the climate will have been severely impacted. At this point, however, this large investment in solar fuels research has not yet produced even a prototype system that is scalable, cost effective, efficient, and stable as determined by a certification process like that for photovoltaic devices. Recently reported devices that 
arguably come closest to this goal are integrated photovoltaicsdriven electrolysis devices. One example is a $64 \mathrm{~cm}^{2}$ modular demonstrator based on triple-junction silicon cells with an efficiency of $3.9 \%$ and a lifetime of more than $40 \mathrm{~h} .^{2} \mathrm{PV}$-driven devices based on III-V semiconductors show higher efficiencies but are more expensive and do not have a scalable design. ${ }^{3}$ At the other end of the spectrum are oxide-based devices, which can be cheap but show poor efficiencies. ${ }^{4}$ Further development of these preprototype systems is needed as a precursor to the required industrial level scale-up to enable solar fuels to have a real impact. In this perspective, we will attempt to evaluate where the field has progressed and where there is still a need for breakthroughs to produce a viable solar fuels industry.

\section{The need for water splitting in a fossil fuel-free society}

The sustainable production of hydrogen is the central challenge for any future clean energy infrastructure that relies on chemical fuels as energy carriers. Ideally, such fuels should be in liquid or gaseous form so that they are easily transported, stored, and used. Not all such chemical fuels contain carbon or nitrogen, but all of them contain hydrogen. Since water is the only universally available, abundant, and sustainable source of hydrogen on the planet, water splitting with sunlight is the key challenge. Figure 1 illustrates a future energy infrastructure in which water splitting plays a central role. While such a completely fossil fuel-free infrastructure is unlikely to become a reality by mid century, many of its components are already in place at a large scale and others will need to be implemented in the near future to assure that they can be scaled up in a timely fashion. The figure also illustrates that hydrogen is an essential base chemical in our food supply chain; without it, we would not be able to make the amounts of fertilizers needed to grow enough food for the world's population. We often forget that we depend on fossil fuels not only for our energy supply but also for our food supply.

\section{Direct versus indirect routes}

Photochemical pathways toward renewable fuel production have always been and may always be in competition with photovoltaics (PV) or wind energy coupled with water electrolysis units. These indirect photo-driven electrolysis systems are already commercially available and offer a way to compensate for the intermittency of solar and wind energy by storing the generated energy in the form of hydrogen. The highest reported efficiency for this approach is an impressive $30 \%$ for a system composed of two series-connected PEM electrolyzers driven by a triple-junction solar cell. ${ }^{5}$ The argument for direct solar photoelectrolysis, in which light absorption and electrocatalysis are integrated into one device, has always been that one system would be cheaper than a system composed of two or more separate devices, i.e., PV connected to electrolyzers. The reasoning is that the costs of the glass, frames, internal wiring and connections, etc. for each of the individual devices are higher than those of the active components, i.e., the silicon in the PV device and the electrodes and membranes in the electrolyzer.
Thus, integration could reduce the overall costs, as is often the case in some multifunction devices such as the combination of a printer, scanner, and fax machine.

While this argument remains valid at the panel or module level, it should be realized that individual component costs make up an increasingly small part of the total system costs. The price of photovoltaic solar panels has fallen dramatically to where now the balance of systems (BOS) costs (external wiring, supports, inverter, permits, etc.) are more than the cost of the panels. ${ }^{6}$ The cost of electrolyzers will likely be brought down significantly with further research and the economies of scale. Indeed, large electrolyzers are used to convert excess hydropowerto-hydrogen in Norway and are currently being installed for other uses in other parts of the world such as wind energy storage in the north of Germany. One should also consider that BOS costs for collecting hydrogen with pipes and membranes over large solar collection areas will likely be much higher than those for a PV-electrolysis installation (even though there may be some savings on the inverters). The most recent estimate for $\mathrm{H}_{2}$ production costs via PEM electrolysis is $\$ 3.40-\$ 6.60 / \mathrm{kg} \mathrm{H}_{2}$ in 2007 US dollars, assuming a variability of $\$ 0.03-\$ 0.08$ per $\mathrm{kW} \mathrm{h}$ in electricity costs. ${ }^{7}$ These electricity prices can nowadays indeed be achieved with PV, as illustrated by a recent successful bid for a 50 MW solar PV field in Europe for $5.38 € \mathrm{ct} / \mathrm{kW} \mathrm{h.}{ }^{8}$ The hydrogen production costs for integrated solar fuel generators are likely to be higher and have been estimated in several studies. ${ }^{9-11}$ One often cited study estimates a cost of $\$ 10.40 / \mathrm{kg} \mathrm{H}_{2}$ assuming a solar-to-hydrogen efficiency of $10 \%$, a panel cost of $\$ 153 / \mathrm{m}^{2}$, and a lifetime of 10 years. ${ }^{11}$ Last but not least, there are significant advantages to generating the amount of hydrogen at the desired pressure on demand where and when it is needed. This is relatively easy to do with electrolyzers, but safely generating high pressures over large solar collection areas comes with serious engineering challenges.

There are, however, also several advantages to be gained by integrating light absorption and electrocatalysis into one single device. One advantage is the relatively small current densities in photoelectrochemical (PEC) devices (10-20 mA/ $\left.\mathrm{cm}^{2}\right)$, about 100 times smaller than the current densities in commercial electrolyzers (1-2 A/ $\mathrm{cm}^{2}$ ). This increases the internal electrolysis efficiency, enabling integrated systems to outperform PV-electrolyzer systems. ${ }^{12}$ Furthermore, the greatly reduced demands on the catalysts may enable the usual Pt- and $\mathrm{IrO}_{X}$ based catalysts to be replaced with low-cost, earth-abundant alternatives. While noble metals currently represent a minor fraction of the cost of the whole electrolysis unit, this is likely to change when the technology is implemented on a multi GW scale. Lower current densities also reduce the loss of the active electrode area due to the presence of gas bubbles. The second advantage of integrated devices is heat management. Assuming (optimistically) an energy conversion efficiency of $20 \%$ and reflection losses of $10 \%$, more than $70 \%$ of the incoming radiation will be converted into heat. In photovoltaic devices, this can lead to operating temperatures of $60-80{ }^{\circ} \mathrm{C}$ and efficiency losses upwards of $10 \% .{ }^{13} \mathrm{In}$ PEC devices, these losses will be much smaller due to effective cooling by the electrolyte solution, especially when using convective flow. ${ }^{14}$

2 - MRS ENERGY \& SUSTAINABILITY // VOLUME 4 // e13 // www.mrs.org/energy-sustainability-journal 


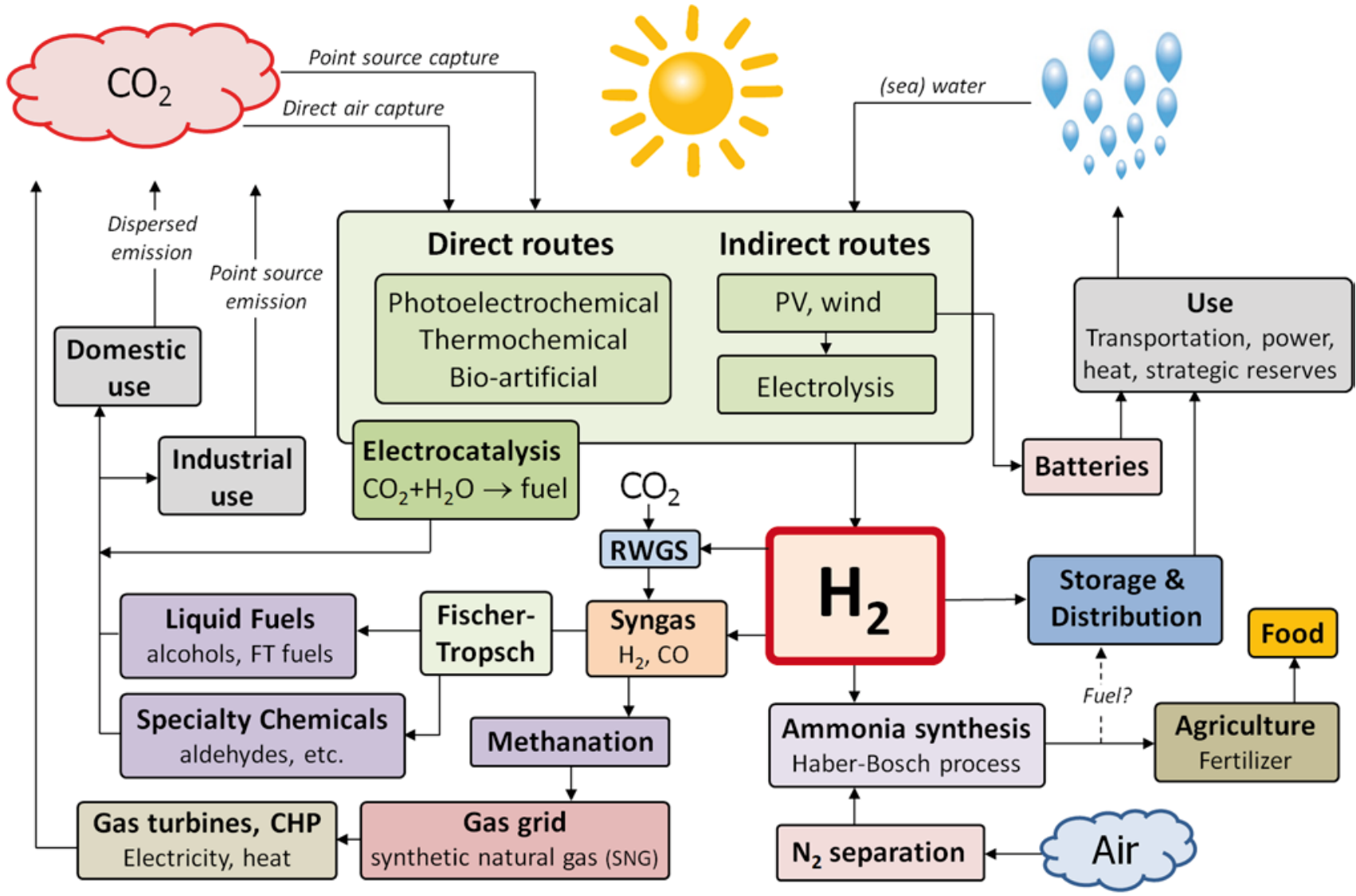

Figure 1. Illustration of a future energy infrastructure based on the renewable and fossil-free conversion of solar energy into a variety of carbon-, nitrogen-, and hydrogen-based chemical fuels. Water splitting, either via direct or indirect routes, plays a crucial role in this scenario. The hydrogen produced via these routes can be fed into the already existing large-scale infrastructure for methanation and Fischer-Tropsch syntheses by reacting it with $\mathrm{CO}_{2}$ to form syngas via the reverse water-gas-shift (RWGS) reaction.

Moreover, higher temperatures enhance the electrochemical reaction kinetics by roughly a factor of 2 per $10{ }^{\circ} \mathrm{C}$ increase (Arrhenius' law). Recent studies have shown that the improvement in the kinetics is larger than the decrease in the photovoltaic properties of the PEC absorber. ${ }^{12,15}$

In summary, it appears to be likely that solar- or wind-driven (indirect) electrolysis will be the sustainable hydrogen production technology of choice for the short-to-medium term (i.e., until mid century). In the medium-to-long term, new device concepts and materials that would benefit from the advantages offered by direct photoelectrolysis routes should be explored.

\section{Water splitting versus $\mathrm{CO}_{2}$ reduction}

If photoelectrochemical systems can be developed and optimized for performance and price, then hydrogen is the preferred product rather than the direct reduction of $\mathrm{CO}_{2}$. The many reasons for this are spelled out in a previous article by one of the authors. ${ }^{16}$ The arguments are summarized here as well in Table 1.

It is clear that direct solar hydrogen generation is quite difficult to accomplish, but it is still much easier than direct $\mathrm{CO}_{2}$ reduction. If one would be able to develop a cost-effective system for renewable hydrogen, it will have an immediate and direct impact on the transportation sector (if fuel cell vehicles become widespread) and on ammonia production. Ammonia production is now a leading $\mathrm{CO}_{2}$ emission source since it consumes $1-2 \%$ of the world's energy supply and almost all the hydrogen comes from either coal gasification (China) or methane reformation. ${ }^{18,19}$ For fueling conventional hydrocarbon-burning vehicles, one might argue that the renewable electrons from sunlight or wind would be better stored directly in the battery of electric vehicles that will be plentiful in the future rather than trying to produce liquids with complex chemistry.

In summary, fundamental research on $\mathrm{CO}_{2}$ reduction is an interesting academic problem but is without a clear path to near term implementation on a large scale; therefore, we argue that it is not practical, nor advisable at this time or the near future, to use renewable energy to directly reduce carbon dioxide produced from burning fossil fuels to reduce $\mathrm{CO}_{2}$ emissions or from the atmosphere to reduce atmospheric concentrations. Instead the better approach, to achieve a renewable fuel-based future energy economy in the urgently needed short timescale, is through the renewable generation of hydrogen. This hydrogen 
Table 1. Practical reasons for not doing direct (photo)electrochemical reduction of $\mathrm{CO}_{2}$.

\begin{tabular}{|c|c|}
\hline Scale & $\begin{array}{l}\text { The scale of } \mathrm{CO}_{2} \text { from fossil fuel burning dwarfs any other chemical process on the planet. } \\
\text { Cement manufacture is the next largest but also produces } \mathrm{CO}_{2} \text {. Therefore to make any dent } \\
\text { in climate mitigation one would have to develop and engineer a chemical infrastructure } \\
\text { at an unprecedented scale }\end{array}$ \\
\hline EROI & $\begin{array}{l}\text { The energy return on investment (EROI) for reducing } \mathrm{CO}_{2} \text { is very unfavorable. Due to the low } \\
\text { Carnot efficiency of fossil fuel plants, it takes many more times the renewable energy } \\
\text { to reduce the produced } \mathrm{CO}_{2} \text { from an electrical generation facility than you produced by } \\
\text { burning the fossil fuel to begin with }\end{array}$ \\
\hline Replace fossil plants with renewables & $\begin{array}{l}\text { Given that solar energy collection requires a large investment to cover large areas and that the } \\
\text { need to collect and purify } \mathrm{CO}_{2} \text { will make the } \mathrm{BOS} \text { costs for a } \mathrm{CO}_{2} \text { reduction facility much } \\
\text { higher than for PV, the investment to convert the } \mathrm{CO}_{2} \text { output to a fuel will be substantially } \\
\text { higher than investing in renewable energy (wind and solar) to replace the fossil fuel plant }\end{array}$ \\
\hline More difficult chemistry & $\begin{array}{l}\text { Although } \mathrm{CO}_{2} \text { reduction is an interesting academic challenge, the difficulty of doing } 6 \text { or } \\
\text { greater electron and proton chemistry on a substrate with limited solubility and with } \\
\text { selectivity will be much more difficult than hydrogen production }\end{array}$ \\
\hline Add hydrogen to carbon sources & $\begin{array}{l}\text { Given that producing solar hydrogen is difficult enough, if accomplished renewable hydrogen } \\
\text { can reduce the greenhouse footprint of coal or biomass via well-known gas phase } \\
\text { chemistry such as water-gas shift and Fischer-Tropsch (Fig. 1). It is already used in } \\
\text { great quantities in oil refining and chemical industries including ammonia }\end{array}$ \\
\hline Minimal atmospheric impact & $\begin{array}{l}\text { Even if you are successful in producing a high-energy liquid fuel from } \mathrm{CO}_{2} \text {, the impact on } \\
\mathrm{CO}_{2} \text { in the atmosphere is minimal since you re-release the carbon to the atmosphere } \\
\text { when it is burned. The impact would be larger if the } \mathrm{CO}_{2} \text { is not converted into fuels but } \\
\text { in high-value products, which may make sense in certain cases (e.g., ethylene) }{ }^{17}\end{array}$ \\
\hline
\end{tabular}

can be used directly in combustion processes (e.g., as additive to other less hydrogenated carbon sources to reduce their greenhouse footprints), in fuel cells, and in chemical processes that now use nonrenewable hydrogen (see, e.g., the left-hand side of Fig. 1).

\section{Alternative photoelectrochemical storage systems}

Recently, there has been a resurgence in the incorporation of energy storage within a photoelectrochemical system. ${ }^{20,21}$ This concept was demonstrated by the Weizmann Institute group in the late 1970s where they incorporated an additional battery electrode to make a three-electrode photoelectrochemical solar cell, where the electrical output could be split between charging the battery redox system and output during daylight and discharging the battery in the dark. ${ }^{22}$ The Texas Instruments system for $\mathrm{HBr}$ photoelectrolysis was another example where inexpensive silicon microspheres with $\mathrm{p}-\mathrm{n}$ and $\mathrm{n}-\mathrm{p}$ junctions were incorporated into panels to produce hydrogen and $\mathrm{Br}_{2}$ in the solution which flowed over the panels. The products were then stored to be recombined in a $\mathrm{H}_{2} / \mathrm{Br}_{2}$ fuel cell during nondaylight hours to produce electrical power. After several hundreds of millions of dollars invested, the project was discontinued due to low oil prices and corrosion issues related to storing and flowing hot $\mathrm{HBr} / \mathrm{Br}_{3}{ }^{-}$solutions. Most of the technology around this system is described in the patent literature. ${ }^{23,24}$ Many years ago, one of the authors also investigated the efficiency and energetics of p-n systems for photoelectrolysis of haloacids. ${ }^{25}$

A similar concept, that is essentially a solar chargeable redox flow battery, is shown in Fig. 2. Instead of trying to split water, the system would work with two kinetically fast one-electron redox couples such as the $\mathrm{V}^{3+} / \mathrm{V}^{2+}$ and $\mathrm{V}^{4+} / \mathrm{V}^{5+}$ couples currently favored in redox flow batteries, but many other redox couple combinations are possible. The additional feature is that when one looks at the system, with its flowing liquid over flat plate collectors, it appears very much like a solar thermal hot water system. So why not take the $\mathbf{8 0 - 8 5 \% ~ o f ~ t h e ~ s o l a r ~ e n e r g y ~ t h a t ~ i s ~ n o t ~}$ collected as stored redox energy and utilize the heat. Adding antifreeze to the electrolyte and incorporating a heat exchanger would essentially mimic the operation of a conventional lowgrade hot water/space heating system. Table 2 summarizes the many advantages such a system would have over the much more difficult to accomplish solar water splitting system. In fact, the system could also be used to generate hydrogen on demand by passing the highly reducing $\mathrm{V}^{2+}$ electrolyte over a catalytic hydrogen evolving electrode such as platinum with the reduction of $\mathrm{V}^{5+}$ to $\mathrm{V}^{4+}$ at the other electrode since a vanadium redox flow battery can have an open circuit voltage of up to $1.5 \mathrm{~V}$. Again, one must consider whether a combined system out-performs two separate systems that can be optimized separately. 


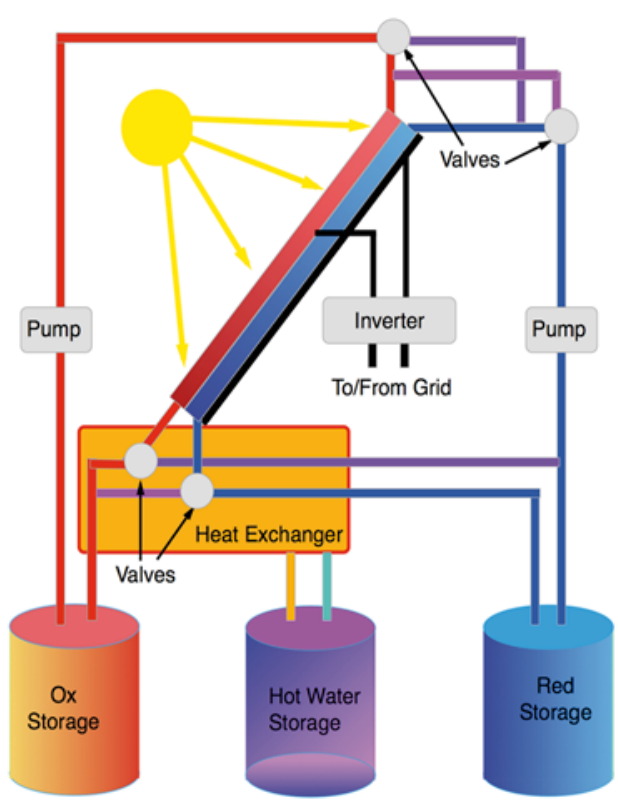

Side View of Collector Pane

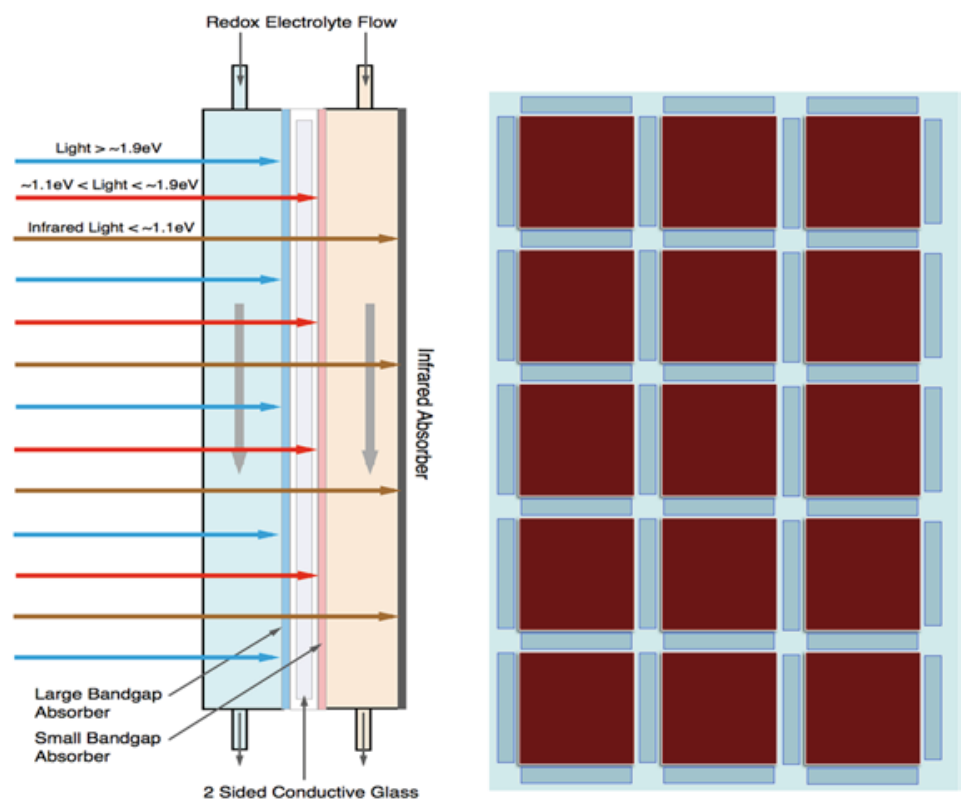

Figure 2. Left: Schematic drawing of the system showing the concept for solar collection and conversion to electricity and stored heat. During charging, a photooxidation reaction will be driven on an n-type semiconductor at one side of the collector, and a photoreduction reaction will be driven on the other electrode by the light that penetrates the front electrode. The infrared light passing through both semiconductors is absorbed by a black absorber at the back of the electrolyte to further heat the electrolyte. Discharge to release the stored electrical energy is accomplished by driving the semiconductors into accumulation using valves to reverse the flow and expose the n-type material to the highly reducing redox electrolyte, while the p-type material is exposed to the highly oxidizing electrolyte. Middle: Side view of one potential design for the solar collector showing the absorbers that are back to back in a tandem configuration on a single glass plate coated on both sides with a conducting transparent oxide. The light path and redox electrolyte flow are also shown. Right: Front view of a potential design for the solar collector showing a pattern of absorbers (maroon) and ion selective membranes (blue) that permit the flow of the counter ions needed to sustain electroneutrality during redox reactions. The redox electrolyte on the front electrode would have to be mostly transparent whereas the electrolyte on the back electrode could be colored.

\section{Research needs for photoelectrochemical fuel production}

Research in the field of photoelectrochemical energy conversion has recently bifurcated in two directions: discovering and developing new materials with proper band gaps and high stability to photocorrosion in electrolytes and depositing corrosionresistant protection layers on well-established PV materials. ${ }^{26}$ The former represents the traditional semiconductor/electrolyte junction where the charge separating junction forms spontaneously upon immersion into the electrolyte, whereas the latter is essentially immersing a solar cell into the electrolyte since the charge/separating junction is isolated from the electrolyte. The authors would prefer that the term photoelectrochemical device be reserved for systems with a true semiconductor/electrolyte interface. This is not to say that the photoelectrochemical device is a preferred configuration since if a buried junction device can be made efficient, stable, and cost effective, it would be a very important advance.

There are some advantages to the liquid junction in a photoelectrochemical device (Table 3). One is that junction formation is perfectly conformal, enabling nanostructuring of the absorber material. Nanostructuring has the advantage of expanding the use of materials with nanometer scale diffusion lengths and lower absorption coefficients since the photogenerated carriers can be created within a diffusion length of the interface as well as extending the space charge layers deeper into the interior of the material. The large surface areas also reduce the turnover rates for any needed catalyst layers that will decrease overpotential losses. This would enable the use of less active, but cheap and earth-abundant catalysts instead of the traditional noble metal candidates. The disadvantage is that the photovoltage would be reduced due to the lower local light intensities (since the photovoltage depends logarithmically on light intensity). ${ }^{13}$ One still needs carrier lifetimes on the order of 20 nanoseconds or more for nanostructuring to be effective. One cannot 'picostructure' to compensate for the picosecond carrier lifetimes that are being measured in some semiconducting oxides.

Several demonstrations of integrated photoelectrochemical devices with buried junctions have recently been reported. Although the active areas are typically small, $<0.5 \mathrm{~cm}^{2}$, impressive efficiencies (up to $14 \%$ ) and lifetimes of up to several days have been reached..$^{3,27}$ These devices are still in an early stage of development and so, it is yet unknown whether they can provide 
Table 2. Summary of eight potential advantages of a hybrid solar electrical/thermal storage system compared to water splitting.

\begin{tabular}{|c|c|}
\hline 1 & $\begin{array}{l}\text { It could replace conventional solar thermal hot water systems and provide stored electrical energy with considerable } \\
\text { savings over two separate systems. A flowing liquid electrolyte allows easy integration of the collection and storage of } \\
\text { solar thermal energy for solar hot water and space heating }\end{array}$ \\
\hline 2 & $\begin{array}{l}\text { The system does not need to collect potentially explosive hydrogen gas over wide areas lowering costs related to large } \\
\text { amounts of piping, compressors, and the potential for large leaks and the small leaks associated with hydrogen diffusion } \\
\text { through materials }\end{array}$ \\
\hline 3 & $\begin{array}{l}\text { No bubbles are produced at the light harvesting semiconductor surface that would scatter light and can adhere } \\
\text { to the semiconductor surface resulting in blocking areas of the semiconductor surface and in some cases } \\
\text { increased corrosion }\end{array}$ \\
\hline 4 & $\begin{array}{l}\text { Catalysts for the multielectron/multiproton water oxidation and reduction reactions are not needed, lowering costs and } \\
\text { eliminating both catalyst stability/poisoning problems and light blocking by catalyst layers and reducing overpotential } \\
\text { losses in the system by as much as } 0.4 \mathrm{~V} \text { thus raising the theoretical achievable efficiency }\end{array}$ \\
\hline 5 & $\begin{array}{l}\text { A large number of fast one-electron redox couples are available for storing the solar energy relieving the constraints on } \\
\text { the band positions of the semiconductor electrode(s) to match only the water oxidation and reduction potentials. Many } \\
\text { more semiconductor material/redox couple combinations will be possible }\end{array}$ \\
\hline 6 & $\begin{array}{l}\text { Utilizing the already large area semiconductor electrodes (reducing overpotential losses) under accumulation as redox } \\
\text { battery electrodes reduces the cost compared to separate PV and redox flow battery combinations }\end{array}$ \\
\hline 7 & Additional redox electrolyte, beyond what is needed for solar load leveling, could be used for general grid load leveling \\
\hline 8 & The system is capable of recovering stored electrical energy on demand with up to $85 \%$ efficiency \\
\hline
\end{tabular}

Table 3. Comparison of semiconductor-liquid junctions versus buried junctions.

\begin{tabular}{|c|c|}
\hline Semiconductor-liquid junction & Buried junction \\
\hline Charge separation at the solid-liquid interface & Charge separation away from the solid-liquid interface \\
\hline $\begin{array}{l}\text { Semiconductor (quasi-)Fermi level can be tuned by redox couple in } \\
\text { solution }\end{array}$ & $\begin{array}{l}\text { Semiconductor band bending is fixed by the contact layer and } \\
\text { electronically de-coupled from the electrolyte }\end{array}$ \\
\hline Near-ideal junction formed by immersion in solution & Junction needs to be engineered and fabricated \\
\hline Junction formation trivial for nanostructured electrodes & $\begin{array}{l}\text { Conformal contacts require specialized tools (e.g., ALD) which may } \\
\text { not work for all contact materials }\end{array}$ \\
\hline Direct illumination of the junction & $\begin{array}{l}\text { Illumination through the contact material which needs to be optically } \\
\text { transparent }\end{array}$ \\
\hline
\end{tabular}

the very long-term stabilization necessary for a practical device. To produce such devices at scale would be technologically challenging since any pinholes or damage in the ultrathin coatings would result in undercutting corrosion and catastrophic failure. However most of the highest efficiency devices available today already depend on costly multijunction solar cell structures with highly optimized thin protection layers.

\section{Materials}

The key active components in a water splitting device are the light absorber(s) and the electrocatalysts. Many research efforts are currently being devoted to the latter, and several efficient and earth-abundant candidates for the hydrogen evolution reaction (HER) over a range of acidic and alkaline conditions are now available. ${ }^{28}$ Earth-abundant candidates for the more difficult 
oxygen evolution reaction (OER) in alkaline conditions and near-neutral $\mathrm{pH}$ have also been identified. ${ }^{28,29}$ What is still missing are earth-abundant candidates for the OER in acidic conditions. While further improvements of OER and HER catalysts are most definitely needed for the development of electrochemical energy storage devices, ${ }^{30}$ we will argue below that the main bottleneck for a true photoelectrochemical device is not the catalyst but the light absorber.

To generate the minimum voltage of $\sim 1.5 \mathrm{~V}$ needed to split water $(1.23 \mathrm{~V}+$ overpotentials $)$, one needs at least two different light absorbers that are electrically connected in series. The highest efficiencies can be obtained with a tandem configuration, in which the bottom and top absorbers absorb complementary parts of the solar spectrum. It has been pointed out many times that the ideal bandgaps for such a dual absorber system are around 1.2 and $1.8 \mathrm{eV} .{ }^{31-33}$ Slightly different band gap combinations may be optimal for the aforementioned solar-driven redox flow battery since the difference between the two redox reactions may be more or less than $1.23 \mathrm{eV}$, and overpotential losses will be less. Silicon $\left(E_{\mathrm{g}}=1.12 \mathrm{eV}\right)$ is close to being an ideal bottom absorber and has already reached the phase of technological maturity. The missing material is a chemically stable top absorber with a band gap of $\sim 1.8 \mathrm{eV}$. While several candidates have been identified, ${ }^{34}$ their photocurrents typically need to be improved by factors of 3-5 and their photovoltages by at least several hundred millivolts to develop a viable water splitting device. Such improvements have been achieved for materials like $\mathrm{BiVO}_{4}$, for which the highest reported photocurrents are now close to the theoretical maximum. ${ }^{35}$ It is the authors' opinion that expanding these efforts to find and improve novel photoabsorbers with smaller bandgaps is more urgent in the quest for efficient photoelectrochemical water splitting devices than reducing the overpotential of the OER and HER catalysts by a few tens of millivolts.

The demands on a semiconductor material for a true photoelectrochemical device, based on a semiconductor-liquid junction without a protection layer, are stringent. It needs to be inexpensive, have a band gap of about $1.8 \mathrm{eV}$, show reasonable carrier lifetimes, and show exceptional long-term stability in electrolyte solutions. There is no fundamental reason that such a material does not exist, but it is equally clear that it has not yet been discovered. Therefore, high throughput techniques for the discovery and optimization of such materials should have a high priority. Given their potential thermodynamic stability, especially needed in a photoanode, metal oxide semiconductors are an obvious choice, but other thermodynamically stable semiconductors such as some nitrides may also be useful.

To accomplish this goal, high throughput combinatorial approaches have already been developed to produce and screen new semiconductor compositions for photoelectrolysis activity in several laboratories around the world, but more laboratories and higher throughput is still needed. ${ }^{36-41}$ Recently, JCAP has published results where several families of new oxide semiconductors were revealed. ${ }^{41}$ Combinatorial techniques are also suited for the optimization of new materials once some photoactive phases are identified. The high $T_{\mathrm{c}}$ superconductors are a good example of the discovery of an oxide with an extraordinary property, and the $T_{\mathrm{c}}$ was quickly improved by a flurry of follow up metal oxide materials with multiple metal incorporations. The hybrid inorganic-organic perovskites for solid-state PV devices is an example of a material that had very unexpected properties and was quickly improved by a stampede of researchers entering the field. Water photoelectrolysis desperately needs such a new material (after all, the original perovskites are very stable metal oxides) due to the urgency of producing a stable, efficient, and cost-effective solar hydrogen system and the significant amount of time that is needed for optimization of engineering devices and scale up. The urgency of developing a photoelectrochemical water splitting device in time to make a difference in the future energy landscape also demands that the synthetic groups and characterization experts also work together to 'fail quickly' when evaluating a potential new semiconductor that is found to have fundamental flaws limiting its performance. An example of such a 'failed' candidate is $\mathrm{Fe}_{2} \mathrm{WO}_{6}$, a new photoanode material with a nearly ideal band gap but a high donor density $\left(>10^{19} \mathrm{~cm}^{-3}\right)$ even after high-temperature annealing, a prohibitively short carrier life time, and unfavorable band edge positions; in our opinion, this material is unlikely to be suitable for water splitting applications and should not be pursued further for this purpose. ${ }^{42}$ The field also needs to recognize when well-studied materials such as $\mathrm{TiO}_{2}, \alpha-\mathrm{Fe}_{2} \mathrm{O}_{3}$, and even $\mathrm{BiVO}_{4}$ (which is certainly useful for scale-up studies but is theoretically limited to $9 \%$ STH efficiency by its 2.4 eV band gap) are not going to solve the problem and refocus their resources and knowledge on the search and optimization of emerging materials. Fundamental research on such materials to determine the limiting factors on its performance can still be justified since it may help to, e.g., identify and/or eliminate voltage limiting defects and recombination centers in the material and related new materials.

\section{Device design}

The number of experimental demonstrations of stand-alone solar water splitting systems has rapidly increased in the past years. ${ }^{43}$ While this is encouraging, nearly all these demonstrations were done with small-area devices, typically $1 \mathrm{~cm}^{2}$ or lesssometimes even less than $1 \mathrm{~mm}^{2}$. When scaling up to sizes beyond $10 \mathrm{~cm}^{2}$, mass and ion transport limitations in the solution phase start to severely affect the efficiencies. ${ }^{44}$ Optimal membrane size and positioning can be used to minimize diffusion distances while still maintaining good $\mathrm{H}_{2}$ and $\mathrm{O}_{2}$ separation, but they introduce additional system complexity and costs. Moreover, one would need to ensure that the membrane does not block the incoming light. Gas collection also becomes a major challenge for large areas. The fabrication of channels may help the collection within the modules themselves, but external piping is unavoidable and will add a lot of complexity to the system. Most (if not all) practical applications require the hydrogen to be produced at pressure. This is easily accomplished in a compact electrolyzer (at an 'electrochemical cost' of about $30 \mathrm{mV}$ per factor of 10 increase in pressure), but it is impractical to make large-area PEC devices robust enough to withstand 
more than a few bars. One can use external compressors, but this adds to the overall complexity and costs. To tackle the various design trade-offs and other general challenges associated with the scale-up, extensive electrochemical engineering efforts are required. This expertise is still under-represented in the PEC field. As chemists and material scientists, the authors are all too aware that their perception of an electrolysis device-and perhaps also that of some of their colleaguesmay be an oversimplified one (Fig. 3). To address this, (electro) chemical engineers need to be brought on board, and multiphysics and multi-scale simulations are needed to guide these efforts. ${ }^{10}$ This should lead to scalable, affordable, efficient, and robust designs for solar fuel generators. From these designs, one can then specify the demands on the various materials and cell components and formulate the very first (urgently needed) roadmap for the development of photoelectrochemical solar fuel devices.
An alternate approach toward device design uses particle-based systems. These are often referred to as "photocatalyst" systems in the literature, but we feel that this term is inappropriate since solar fuel-producing reactions are thermodynamically uphill and, therefore, photosynthetic in nature. The main advantage of such systems would be that they are less complex and can potentially produce hydrogen at the lowest cost provided that sufficiently high efficiencies can be achieved. ${ }^{11}$ However particle-based systems must fulfill two critical conditions:

(i) Explosive mixtures have to be avoided.

(ii) Chemical recombination or back reactions must be suppressed.

A single explosive accident would doom the technology much like how the Hindenburg disaster led to the end of the passenger airship. Several co-catalysts have been identified that can suppress the back reaction. ${ }^{45-47}$ Dual bed particle suspension

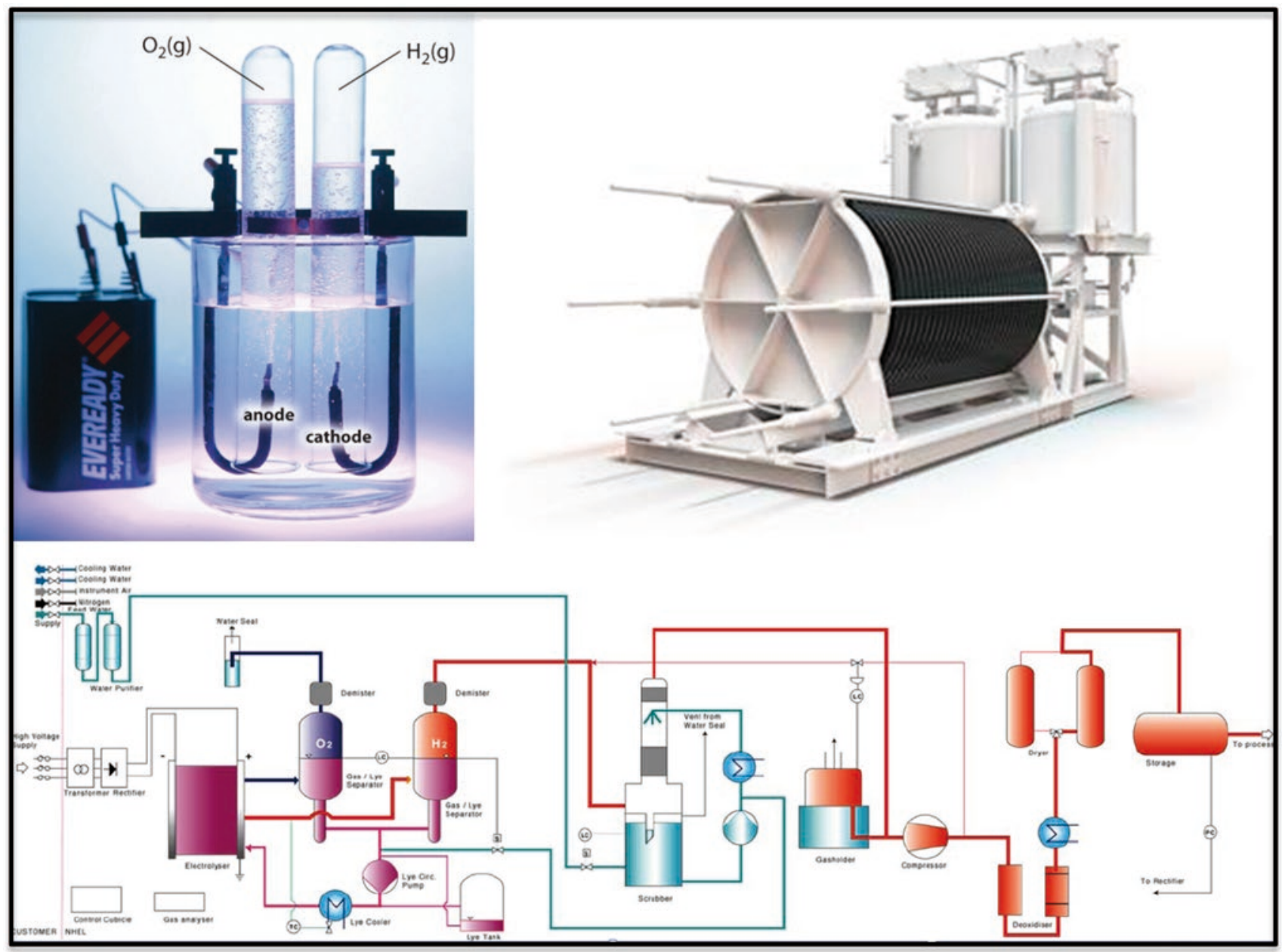

Figure 3. Above left: A chemist's view of an electrolyzer (from: https://chem.libretexts.org/Core/Analytical_Chemistry/Electrochemistry/Electrolytic_Cells/ Electrolysis_I, under the Creative Commons Attribution-Noncommercial-Share Alike 3.0 United States License). Top right: A 485 Nm³/h, 2 MW industrial electrolyzer that runs at $400 \mathrm{~V}$ and about $5000 \mathrm{~A}$ (photograph and specifications provided by Sertronic, http://www.sertronic.com). Bottom: An electrochemical engineer's views of an electrolyzer showing the added complexity of a multimegawatt installation. 
systems can be used to keep the reaction products separated by using a redox mediator to shuttle charges between the two solar collecting areas. ${ }^{48}$ Scale up is, in principle, straightforward, ${ }^{11}$ provided the redox concentration can be made high enough to avoid transport limitations without absorbing too much of the incident light. The main disadvantage of such systems is that they require twice the photon capture area, limiting the theoretical efficiency to $\sim 15 \% .{ }^{11}$ Typical efficiencies achieved for such systems are less than $1 \% .{ }^{49}$ Another solution would be to rapidly sequester the hydrogen while it is still dissolved in the solution phase at a rate greater than any back reaction.

Another novel approach to solar fuel generation is Nocera et al.'s recent demonstration of a hybrid water splittingbiosynthetic system, where dissolved photoelectrochemically produced hydrogen and $\mathrm{CO}_{2}$ are consumed by an engineered bacterium and converted into biomass and higher alcohols $\left(\mathrm{C}_{3}-\mathrm{C}_{5}\right){ }^{50}$ While such systems still have a long way to go before becoming practical, it illustrates the creative thinking and new ideas needed to achieve breakthroughs in solar water splitting.

\section{Benchmarking}

Further development of PEG water splitting devices requires the development of procedures for the reliable benchmarking of efficiencies and stability. Such procedures are well established for the field of PV, where one can send a PV cell to the National Renewable Energy Laboratory (NREL) in the US, the Fraunhofer Institute for Solar Energy Systems in Germany, the National Institute of Advanced Industrial Science and Technology in Japan, or the European Solar Test Installation in Italy to get a certified efficiency. Such facilities do not yet exist for photoelectrochemical or photo-driven electrochemical devices because (i) relatively few stand-alone solar fuel generators have been reported so far and (ii) establishing reliable benchmarking procedures is far more complicated than for photovoltaic devices. ${ }^{51-53}$ The complications arise from having such a wide variety of components, device configurations, and reaction products to deal with, all of which would have to be transported to the benchmarking laboratory. Water splitting devices typically have multiple containers, catalysts, and electrodes. The presence of optical windows, membranes, and liquid as well as gaseous phases further complicates matters. Another challenge is stability: PEC devices are more likely to degrade than solidstate PV devices, and accelerated testing at high light intensities will likely be misleading due to the nonlinear dependence of multielecton or multihole corrosion reactions.

If the field advances further to where researchers and engineers are actually producing viable devices for solar water splitting, there will be an increasing need for a standard procedure or-better yet-a certification by an independent laboratory. It is useful to at least start the conversation about how this should be done. JCAP did perform a useful service when, after considerable deliberation, they came up with the criteria for evaluation of water oxidation and reduction catalysts to at least provide a starting point to compare the exploding number of these catalysts reported in the last few years. ${ }^{54}$ Hopefully, the field can quickly reach a point where they can show a universally accepted chart, like the ubiquitous NREL chart for PV efficiencies that shows progress over time in solar fuel device efficiencies for different device configurations. JCAP has made a first attempt at such a chart that resonates well in the field, ${ }^{43}$ but much work needs to be done to ensure the data points are measured and reported in a consistent and universally agreed fashion. There was one historical and several recent publications on best procedures for defining configurations, light sources, and the stability criteria for measuring more artifact-free solar hydrogen conversion efficiencies in a researcher's own lab. ${ }^{51,52,55,56}$ There is a clear need to expand these efforts and establish an official benchmarking laboratory to certify the efficiency of a device. This will reduce arguments on claims of record efficiencies and provide guidance for potential investment and industrial partners to scale up systems.

\section{Conclusions}

Hydrogen will play a key role in any future fossil fuel-free energy infrastructure that relies on chemical fuels as energy carriers. Since water is the only abundant source of hydrogen on the planet and sunlight is the most abundant energy source, developing the technology for solar-driven water splitting on a multi-GW scale is and will become a central challenge. This technology will likely be based on the currently available PV-powered electrolysis until well into the 21 st century. The next logical step is to integrate light absorption and electrochemistry into a single device; such 'direct' photoelectrochemical routes offer several advantages and may become the technology of choice in the future. However, significant R\&D efforts and breakthroughs in the following areas are needed to accomplish this goal:

(1) Materials: new chemically stable semiconductors with a band gap between 1.5 and $2.0 \mathrm{eV}$ and sufficiently long carrier lifetimes need to be developed. This requires high-throughput experimentation and effective collaborations between experts. It also requires a willingness to 'fail quickly' and avoid mistakes of the past, such as the 40-year efforts on trying to make a good solar absorber from a wide-bandgap material such as $\mathrm{TiO}_{2}$. These efforts are better spent on finding and characterizing novel absorber materials.

(2) Device design: once the materials challenges are solved, mass transport limitations are the next major bottleneck in development of photoelectrochemical devices. Since these limitations only become apparent for active device areas beyond a few $\mathrm{cm}^{2}$, we need to shift our efforts toward larger area devices and strengthen the field by bringing in electrochemical engineers.

(3) Benchmarking: to facilitate a realistic comparison between different devices and steer scale-up efforts, development of standardized methods for measuring efficiencies and stabilities need to be implemented leading to official benchmarking laboratories that can certify device performance. 
Rapid progress in these areas requires a careful balancing act. We need to support innovative and risky approaches and avoid becoming entrenched in pathways that may appear most viable in the short-to-medium term but cannot in the long-term result in an efficient enough system to justify its expense. At the same time, we need to keep our eye on the final goal and avoid distractions that may be academically interesting but that do not lead to real progress. Only then will the photoelectrochemical storage of solar energy have a chance to make a difference in the sustainable energy infrastructure of the future.

\section{Acknowledgments}

BAP acknowledges the U.S. Department of Energy, Office of Science, Basic Energy Sciences, Division of Chemical Sciences for financial support through Grant DE-SC0007115 and the Alexander von Humboldt Foundation for supporting collaborative visits to Germany. RK acknowledges support from the German Bundesministerium für Bildung and Forschung (BMBF) through project "MeOx4H2" (03SF0478A).

\section{REFERENCES:}

1. Our (conservative) estimate of the total expenditure is based on data in the following presentation, to which we added the budgets of several other European initiatives that we are aware of: S. Dasgupta: Global Centers for Solar Fuels \& Artificial Photosynthesis [Online]. Available at: http:// www.stepc.gr/uploads/Dasgupta.pdf (accessed October 15, 2017).

2. Turan B., Becker J.P., Urbain F., Finger F., Rau U., and Haas S.: Upscaling of integrated photoelectrochemical water-splitting devices to large areas. Nat. Commun. 7, 12681 (2016)

3. May M.M., Lewerenz H.J., Lackner D., Dimroth F., and Hannappel T.: Efficient direct solar-to-hydrogen conversion by in situ interface transformation of a tandem structure. Nat. Commun. 6, 8286 (2015).

4. Bornoz P., Abdi F.F., Tilley S.D., Dam B., van de Krol R., Grätzel M., and Sivula K.: A bismuth vanadate-cuprous oxide tandem cell for overall solar water splitting. J. Phys. Chem. C118, 16959 (2014).

5. Jia J.Y., Seitz L.C., Benck J.D., Huo Y.J., Chen Y.S., Ng J.W.D., Bilir T., Harris J.S., and Jaramillo T.F.: Solar water splitting by photovoltaicelectrolysis with a solar-to-hydrogen efficiency over $30 \%$. Nat. Commun. 7, 12237 (2016)

6. Chung D., Davidson C., Fu R., Ardani K., and Margolis R.: U.S. Photovoltaic Prices and Cost Breakdowns: Q1 2015 Benchmarks for Residential, Commercial, and Utility-Scale Systems [Report] (National Renewable Energy Laboratory (NREL), Golden, CO, 2015).

7. Miller E., Ainscough C., and Talapatra A.: Hydrogen Production Status 2006-2013 [Report] (United States Department of Energy, Washington, DC, 2014).

8. Bundesnetzagentur announces successful bids in photovoltaic auction with Denmark [Online]. Available at: https://www.bundesnetzagentur.de/ SharedDocs/Pressemitteilungen/EN/2016/161128_PVDK.html (accessed October 15, 2017).

9. Newman J., Hoertz P.G., Bonino C.A., and Trainham J.A.: Review: An economic perspective on liquid solar fuels. J. Electrochem. Soc. 159, A1722 (2012).

10. Dumortier M., Tembhurne S., and Haussener S.: Holistic design guidelines for solar hydrogen production by photo-electrochemical routes. Energy Environ. Sci. 8, 3614 (2015).

11. Pinaud B.A., Benck J.D., Seitz L.C., Forman A.J., Chen Z.B., Deutsch T.G., James B.D., Baum K.N., Baum G.N., Ardo S., Wang H.L., Miller E., and Jaramillo T.F.: Technical and economic feasibility of centralized facilities for solar hydrogen production via photocatalysis and photoelectrochemistry. Energy Environ. Sci. 6, 1983 (2013).

12. Haussener S., Hu S., Xiang C.X., Weber A.Z., and Lewis N.S.: Simulations of the irradiation and temperature dependence of the efficiency of tandem photoelectrochemical water-splitting systems. Energy Environ. Sci. 6, 3605 (2013).

13. Würfel P.: Physics of Solar Cells (Wiley-VCH, Weinheim, 2005).

14. Tembhurne S. and Haussener S.: Integrated photo-electrochemical solar fuel generators under concentrated irradiation II. Thermal management a crucial design consideration. J. Electrochem. Soc. 163, H999 (2016).

15. Ye X., Melas-Kyriazi J., Feng Z.A., Melosh N.A., and Chueh W.C.: A semiconductor/mixed ion and electron conductor heterojunction for elevated-temperature water splitting. Phys. Chem. Chem. Phys. 15, 15459 (2013).

16. Parkinson B.: Advantages of solar hydrogen compared to direct carbon dioxide reduction for solar fuel production. ACS Energy Lett. 1, 1057 (2016).

17. Reller C., Krause R., Volkova E., Schmid B., Neubauer S., Rucki A., Schuster M., and Schmid G.: Selective electroreduction of $\mathrm{CO}_{2}$ toward ethylene on nano dendritic copper catalysts at high current density. Adv. Energy Mater. 7, 1602114 (2017).

18. LeCompte C.: Fertilizer Plants Spring up to Take Advantage of U.S. 's Cheap Natural Gas, Scientific American [Online]. Available at: https:// www.scientificamerican.com/article/fertilizer-plants-grow-thanks-tocheap-natural-gas/ (accessed August 7, 2017).

19. Fertilizer and crop production [Online]. Available at: http://chemistry. need.org/content.asp?contentid=147 (accessed August 11, 2017).

20. Yu M.Z., MeCulloch W.D., Huang Z.J., Trang B.B., Lu J., Amine K., and Wu Y.Y.: Solar-powered electrochemical energy storage: An alternative to solar fuels. J. Mater. Chem. A 4, 2766 (2016).

21. Wedege K., Azevedo J., Khataee A., Bentien A., and Mendes A.: Direct solar charging of an organic-inorganic, stable, and aqueous alkaline redox flow battery with a hematite photoanode. Angew. Chem., Int. Ed. 55, 7142 (2016).

22. Manassen J., Hodes G., and Cahen D.: Photoelectrochemical energyconversion and storage-polycrystalline CdSe cell with different storage modes. J. Electrochem. Soc. 124, 532 (1977).

23. Porter W.A., Lathrop J.W., and Kilby J.S.: Solar energy conversion. U.S. Patent No. 0402132, 1975.

24. Porter W.A., Lathrop J.W., and Kilby J.S.: Light energy conversion. U.S. Patent No. 4100051, 1976.

25. Fornarini L., Nozik A.J., and Parkinson B.A.: The energetics of P/N photoelectrolysis cells. J. Phys. Chem. 88, 3238 (1984).

26. Hu S., Lewis N.S., Ager J.W., Yang J.H., McKone J.R., and Strandwitz N.C.: Thin-film materials for the protection of semiconducting photoelectrodes in solar-fuel generators. J. Phys. Chem. C 119, 24201 (2015).

27. Verlage E., Hu S., Liu R., Jones R.J.R., Sun K., Xiang C.X., Lewis N.S., and Atwater H.A.: A monolithically integrated, intrinsically safe, $10 \%$ efficient, solar-driven water-splitting system based on active, stable earth-abundant electrocatalysts in conjunction with tandem III-V light absorbers protected by amorphous $\mathrm{TiO}_{2}$ films. Energy Environ. Sci. 8, 3166 (2015).

28. McCrory C.C.L., Jung S., Ferrer I.M., Chatman S.M., Peters J.C., and Jaramillo T.F.: Benchmarking hydrogen evolving reaction and oxygen evolving reaction electrocatalysts for solar water splitting devices. J. Am. Chem. Soc. 137, 4347 (2015).

29. Kanan M.W. and Nocera D.G.: In situ formation of an oxygen-evolving catalyst in neutral water containing phosphate and $\mathrm{Co}^{2+}$. Science 321, 1072 (2008).

30. Seh Z.W., Kibsgaard J., Dickens C.F., Chorkendorff I.B., Norskov J.K., and Jaramillo T.F.: Combining theory and experiment in electrocatalysis: Insights into materials design. Science 355, 146 (2017).

31. Seitz L.C., Chen Z.B., Forman A.J., Pinaud B.A., Benck J.D., and Jaramillo T.F.: Modeling practical performance limits of photoelectrochemical water splitting based on the current state of materials research. ChemSusChem 7, 1372 (2014).

32. Weber M.F. and Dignam M.J.: Efficiency of splitting water with semiconducting photoelectrodes. J. Electrochem. Soc. 131, 1258 (1984).

33. Hu S., Xiang C.X., Haussener S., Berger A.D., and Lewis N.S.: An analysis of the optimal band gaps of light absorbers in integrated tandem photoelectrochemical water-splitting systems. Energy Environ. Sci. 6, 2984 (2013).

34. Sivula K. and van de Krol R.: Semiconducting materials for photoelectrochemical energy conversion. Nat. Rev. Mater. 1,15010 (2016). 
35. Pihosh Y., Turkevych I., Mawatari K., Uemura J., Kazoe Y., Kosar S., Makita K., Sugaya T., Matsui T., Fujita D., Tosa M., Kondo M., and Kitamori T.: Photocatalytic generation of hydrogen by core-shell $\mathrm{WO}_{3} / \mathrm{BiVO}_{4}$ nanorods with ultimate water splitting efficiency. Sci. Rep. 5, 11141 (2015).

36. Woodhouse M. and Parkinson B.A.: Combinatorial approaches for the identification and optimization of oxide semiconductors for efficient solar photoelectrolysis. Chem. Soc. Rev. 38, 197 (2009).

37. Rowley J.G., Do T.D., Cleary D.A., and Parkinson B.A.: Combinatorial discovery through a distributed outreach Program: Investigation of the photoelectrolysis activity of p-type $\mathrm{Fe}, \mathrm{Cr}, \mathrm{Al}$ oxides. ACS Appl. Mater. Interfaces 6, 9046 (2014).

38. Baeck S.H., Jaramillo T.F., Brandli C., and McFarland E.W.: Combinatorial electrochemical synthesis and characterization of tungsten-based mixed-metal oxides. J. Comb. Chem. 4, 563 (2002).

39. Keller D.A., Ginsburg A., Barad H.N., Shirnanovich K., Bouhadana Y., Rosh-Hodesh E., Takeuchi I., Aviv H., Tischler Y.R., Anderson A.Y., and Zaban A.: Utilizing pulsed laser deposition lateral inhomogeneity as a tool in combinatorial material science. ACS Comb. Sci. 17, 209 (2015).

40. Koinuma H. and Takeuchi I.: Combinatorial solid-state chemistry of inorganic materials. Nat. Mater. 3, 429 (2004).

41. Yan Q.M., Yu J., Suram S.K., Zhou L., Shinde A., Newhouse P.F., Chen W., Li G., Persson K.A., Gregoire J.M., and Neaton J.B.: Solar fuels photoanode materials discovery by integrating high-throughput theory and experiment. Proc. Natl. Acad. Sci. U. S. A. 114, 3040 (2017).

42. Abdi F.F., Chemseddine A., Berglund S.P., and van de Krol R.: Assessing the suitability of iron tungstate $\left(\mathrm{Fe}_{2} \mathrm{WO}_{6}\right)$ as a photoelectrode material for water oxidation. J. Phys. Chem. C 121, 153 (2017).

43. Ager J.W., Shaner M.R., Walczak K.A., Sharp I.D., and Ardo S.: Experimental demonstrations of spontaneous, solar-driven photoelectrochemical water splitting. Energy Environ. Sci. 8, 2811 (2015).

44. Modestino M.A., Hashemi S.M.H., and Haussener S.: Mass transport aspects of electrochemical solar-hydrogen generation. Energy Environ. Sci. 9, 1533 (2016).

45. Sasaki Y., Iwase A., Kato H., and Kudo A.: The effect of co-catalyst for Z-scheme photocatalysis systems with an $\mathrm{Fe}^{3+} / \mathrm{Fe}^{2+}$ electron mediator on overall water splitting under visible light irradiation. J. Catal. 259, 133 (2008).

46. Maeda K., Teramura K., Lu D., Saito N., Inoue Y., and Domen K.: Noble-metal $/ \mathrm{Cr}_{2} \mathrm{O}_{3}$ core/shell nanoparticles as a cocatalyst for photocatalytic overall water splitting. Angew. Chem., Int. Ed. 45, 7806 (2006).

47. Dionigi F., Vesborg P.C.K., Pedersen T., Hansen O., Dahl S., Xiong A.K., Maeda K., Domen K., and Chorkendorff I.: Suppression of the water splitting back reaction on $\mathrm{GaN}: \mathrm{ZnO}$ photocatalysts loaded with core/shell cocatalysts, investigated using a mu-reactor. J. Catal. 292, 26 (2012).

48. Sayama K., Mukasa K., Abe R., Abe Y., and Arakawa H.: Stoichiometric water splitting into $\mathrm{H}_{2}$ and $\mathrm{O}_{2}$ using a mixture of two different photocatalysts and an $\mathrm{IO}_{3}{ }^{-} / \mathrm{I}^{-}$shuttle redox mediator under visible light irradiation. Chem. Commun., 0(23), 2416 (2001).

49. Miseki Y., Fujiyoshi S., Gunji T., and Sayama K.: Photocatalytic Z-scheme water splitting for independent $\mathrm{H}_{2} / \mathrm{O}_{2}$ production via a stepwise operation employing a vanadate redox mediator under visible light. J. Phys. Chem. C 121, 9691 (2017).

50. Liu C., Colon B.C., Ziesack M., Silver P.A., and Nocera D.G.: Water splitting-biosynthetic system with $\mathrm{CO}_{2}$ reduction efficiencies exceeding photosynthesis. Science 352, 1210 (2016).

51. May M.M., Lackner D., Ohlmann J., Dimroth F., van de Krol R., Hannappel T., and Schwarzburg K.: On the benchmarking of multijunction photoelectrochemical fuel generating devices. Sustainable Energy Fuels 1, 492 (2017).

52. Döscher H., Young J.L., Geisz J.F., Turner J.A., and Deutsch T.G.: Solar-tohydrogen efficiency: Shining light on photoelectrochemical device performance. Energy Environ. Sci. 9, 74 (2016).

53. Döscher H., Geisz J.F., Deutsch T.G., and Turner J.A.: Sunlight absorption in water-efficiency and design implications for photoelectrochemical devices. Energy Environ. Sci. 7, 2951 (2014).

54. McCrory C.C.L., Jung S.H., Peters J.C., and Jaramillo T.F.: Benchmarking heterogeneous electrocatalysts for the oxygen evolution reaction. J. Am. Chem. Soc. 135,16977 (2013).

55. Chen Z.B., Jaramillo T.F., Deutsch T.G., Kleiman-Shwarsctein A., Forman A.J., Gaillard N., Garland R., Takanabe K., Heske C., Sunkara M., McFarland E.W., Domen K., Miller E.L., Turner J.A., and Dinh H.N.: Accelerating materials development for photoelectrochemical hydrogen production: Standards for methods, definitions, and reporting protocols. J. Mater. Res. 25, 3 (2010).

56. Parkinson B.: On the efficiency and stability of photoelectrochemical devices. Acc. Chem. Res. 17, 431 (1984) 